\title{
Approach to an obstetric prognosis scale: The modified SOFA scale
}

\author{
Lourdes A. Blanco Esquivel ${ }^{1}$, Jorge Macia Urbina ${ }^{1}$ and Hugo Mendieta Zerón ${ }^{1,2}$ \\ Ghana Med J 2016; 50(3): 129-135 DOI: http://dx.doi.org/10.4314/gmj.v50i3.3
}

1"Mónica Pretelini Sáenz" Maternal-Perinatal Hospital (HMPMPS), Instituto de Salud del Estado de México (ISEM).. Paseo Tollocan, Moderna de la Cruz, 50180 Toluca, México. ${ }^{2}$ Ciprés Grupo Médico (CGM) and Asociación Científica Latina (ASCILA). Felipe Villanueva sur 700, Col. Morelos, 50120, Toluca, México

Corresponding author: Dr. Hugo Mendieta Zerón

E-mail: mezh_74@yahoo.com

Conflict of interest: None declared

\section{SUMMARY}

Background: Severe obstetric morbidity constitutes a serious problem worldwide; however, an effective obstetrical prognosis scale is still missing.

Objective: To propose a modified Sequential Organ Failure Assessment Score (SOFA) score based on time before reaching specialized medical attention.

Method: This was an ambispective, descriptive study, including all women treated at the Obstetrical Intensive Care Unit (OICU) of the "Mónica Pretelini Sáenz" Maternal-Perinatal Hospital (HMPMPS), Toluca, Mexico, from June 2009 to June 2013. The patient's SOFA score and clinical evolution were registered daily. A modified obstetrical SOFA scale was constructed adjusting the value of 180 instead of 200 in the punctuation column of 3 for the $\mathrm{PaO}_{2} / \mathrm{FiO}_{2}$ ratio and adding a file of disease evolution time with sepsis prior to reaching specialized medical attention.

Results: Two hundred thirty two patients, with an average age (SD) of $26.42( \pm 7.54)$ years, mean gestational age of $33( \pm 7.5)$ weeks were included in the study; 118 suffered from pre-eclampsia, 56 obstetric haemorrhages, 41 eclampsia ( 25 preceded by pre-eclampsia) and 23 , sepsis. ROC curves showed a higher area under the curve (AUC) for the modified SOFA $(0.868 ; \mathrm{p}<0.001)$ than SOFA $(0.796 ; \mathrm{p}=0.003)$, in the prediction of maternal mortality.

Conclusions: The SOFA score, taking into account a lower value for the Kirby index and a threshold time of 12-h with sepsis before getting specialized medical attention, shows a good predictive value for maternal death and could be considered for evaluating the severity of complicated obstetrical patients.

Funding: None declared

Keywords: Intensive Care Units, maternal mortality, Sequential Organ Failure

\section{INTRODUCTION}

Severe obstetric morbidity constitutes a serious problem worldwide. ${ }^{1,2}$ limiting developing countries in reaching the United Nations World Health Organization (U.N. WHO) Fifth Millennium Development Goal (MDG5) set in 2000 , due in part to inadequate clinical work-ups and monitoring, missed and incorrect diagnoses, delayed or incorrect treatment, delayed referrals and transfers, patients not being stabilized prior to referral, and outright negligence. $^{3-5}$

The WHO defines maternal mortality as a death of a woman while pregnant or within 42 days after delivery, irrespective of pregnancy duration and site, being any cause related with worsening of the pregnancy or its management but not from accidental or incidental causes. ${ }^{6}$
A limited number of conditions account for the majority of maternal deaths (haemorrhage, hypertensive disorders, sepsis/infections, and obstructed labour). ${ }^{7}$ Many classification systems have been developed to recognize early deterioration in critically ill patients, some based only on sepsis, ${ }^{8}$ while others were designed to evaluate systemic damage. 9

Among the existing scales, that proposed by the $\mathrm{WHO}^{10}$ includes more information in the case of pregnancy; however, it is a tool for the purpose of establishing morbidity and mortality retrospectively and is not as useful in Critical care units (CCU) for prospective purposes. 
Likewise, an important scoring system is the Sequential Organ Failure Assessment (SOFA), which describes the clinical course of the patient as a marker for the degree of organ dysfunction and a predictor for mortality. The organic functions used in this scoring system are pulmonary, cardiovascular, coagulation, hepatic, renal, and neurological. ${ }^{11}$

To date, assessment of organ dysfunction/failure in obstetrical patients remains difficult. We are aware of previous efforts to compare SOFA vs. the Acute Physiology and Chronic Health Evaluation (APACHE), ${ }^{12}$ and of the recently released Sepsis in Obstetrics Score (S.O.S.). ${ }^{13}$

In our third level hospital we face two main challenges to reach a maternal mortality decrement, preeclampsia/eclampsia and sepsis. Since in pregnancy the physiological parameters are modified and that time prior to reaching medical care is critical for the clinical outcome in critical obstetric patients, ${ }^{14}$ the purpose of this study was to propose an obstetrical SOFA score (O-SOFA).

\section{METHODS}

\section{Study design}

This was an ambispective, descriptive study conducted at the Obstetrical Intensive Care Unit (OICU), "Mónica Pretelini Sáenz" Maternal-Perinatal Hospital (HMPMPS), Health Institute of the State of Mexico (ISEM), Toluca, State of Mexico, Mexico.

\section{Patients}

All patients treated at the HMPMPS OICU from June 2009 to June 2013 were included in the study. Women seen at the OICU without an obstetrical complication were excluded from the study and those with incomplete clinical or biochemical information were eliminated. Duration of follow-up was up to the day of discharge.

\section{General data}

From all patients, gyneco-obstetrical data, laboratory studies, diagnosis on admission to the OICU, organ dysfunctions, sepsis, therapeutic interventions, and their outcome, surgical complications, length-of-stay, SOFA score, and death were recorded in an electronic open file, developed by the researchers, ${ }^{15}$ and these then were exported to an Excel data sheet in which O-SOFA score was calculated.

Definition of the Systemic Inflammatory Response Syndrome (SIRS) and sepsis, as described by Bone, ${ }^{16}$ were utilized for the determination of the severity of infection on admission.

\section{Sampling and laboratory analysis}

All patients admitted into the OICU underwent standard care, including the following daily, routine laboratory tests: albumin $(\mathrm{mg} / \mathrm{dl})$; cholesterol $(\mathrm{mg} / \mathrm{dl})$; creatinine (mg/dl); glucose (mg/dl); triglycerides (mg/dl); uric acid (mg/dl) (Dimension R × L Max, Dade Behring, USA) and hemoglobin (g/dl) (Advia 120, Bayer Health).

All of these tests were measured at the HMPMPS according to standardized procedures recommended by the International Federation of Clinical Chemistry and Laboratory Medicine (IFCC). Gasometric analyses were conducted in the Gem ${ }^{\circledR}$ Premier 3000 (Instrumentation Laboratory, USA).

\section{Statistical analysis}

Results are presented as means \pm 1 SD for continuous variables with Gaussian-shaped distribution and as (relative) frequencies for nominal categorical variables. Time was measured as days from admission to the OICU. Cox Forward and Backward Regression models and a linear regression model with creatinine, Kirby testing, and platelets as predictive variables for maternal death were performed. Finally, Receiver operating curves (ROC) were used to obtain sensitivity and specificity for Kirby, $\mathrm{FiO}_{2}$, creatinine, SOFA, and O-SOFA. In all cases, a $\mathrm{p} \leq 0.05$ was considered statistically significant. All tests were performed with the SPSS ver. 20 statistical software program (SPPS, Inc., Chicago, IL, USA).

\section{Ethics}

The study was approved by the HMPMPS Institutional Review Board (code 2013-11-224), following the guidelines of the Helsinki Declaration (Fortaleza, Brazil). The need for informed consent was waived. The data collected were maintained anonymous.

\section{RESULTS}

Two hundred fifty nine (259) patients were admitted to the OICU of the HMPMPS from June 2009 to June 2013. From this initial group, 27 were excluded due to incomplete information (lack of 24-h creatinine depuration) and 232 individuals remained; 195 of these were referred from another health unit.

Average age was $26 \pm 4$ years (range, 13-45 years) with an average stay in the Critical care unit (CCU) of $4 \pm$ 4.1 days (range, $1-25$ days). Mean gestational age of the patients was 33 weeks \pm 7.5 weeks (range, 6-42.4 days). The general characteristics of our population are depicted in Table 1.

During the study period, we saw 118 patients with severe pre-eclampsia; 41 of these suffered from eclampsia (including 25 cases of severe pre-eclampsia that progressed to eclampsia). 
According to Near-Miss definitions, ${ }^{10}$ frequency of organ dysfunction was as follows: haematological, 67 $(28.87 \%)$; cardiovascular, $55(23.7 \%)$; renal, 37 (15.94\%); uterine, 37 (15.94\%); neurological, 35 $(15.08 \%)$; respiratory, 29 (12.5\%), and hepatic, 24 $(10.34 \%)$.

Table 1 General characteristics of our population

\begin{tabular}{|l|l|}
\hline Item & N (\%) \\
\hline Age $(\mathrm{n}=232)$ & \\
\hline$<\mathbf{2 0}$ years & $49(21.12)$ \\
\hline $\mathbf{2 0}-\mathbf{2 9}$ years & $105(45.25)$ \\
\hline $\mathbf{3 0 - 3 9}$ years & $73(31.46)$ \\
\hline$>$ 39 years & $11(4.74)$ \\
\hline Resolution of pregnancy at gestational age & \\
\hline$<\mathbf{2 8}$ weeks & $34(14.65)$ \\
\hline between 28 and 32 weeks & $40(17.24)$ \\
\hline between 33 and 36 weeks & $57(24.56)$ \\
\hline$>\mathbf{3 6}$ weeks & $115(49.56)$ \\
\hline Type of delivery & \\
\hline Vaginal & $156(67.24)$ \\
\hline Caesarian & $51(21.98)$ \\
\hline Abortions & $6(2.58)$ \\
\hline Stillbirths & $19(8.18)$ \\
\hline Primary determinant factors of near miss & \\
\hline Hypertensive syndromes & $134(57)$ \\
\hline Hemorrhage & $51(21.98)$ \\
\hline Sepsis & $23(9.91)$ \\
\hline
\end{tabular}

In addition, 23 patients had criteria for sepsis (9\%), and 36 laparotomies (15.51\%) were performed on patients participating in the study. One hundred fourteen patients required the transfusion of blood products.

In 182 patients, prophylactic oxytocin was used, and in eight women, other medications were required to prevent bleeding. As treatment for obstetric postpartum haemorrhage, 23 patients were given Oxytocin, 15 Ergometrine, 21 Misoprostol, and 22 other drugs. In 18 patients, there was the need for retained abortion removal and a BakriтM balloon was placed in one patient. In seven patients, uterine or hypogastric ligation was performed. A hysterectomy was performed in 42 patients, and nine patients underwent abdominal packing. A total of nine maternal deaths $(3.8 \%)$ during pregnancy, childbirth, or puerperium were recorded. Of the reported maternal deaths, there were four from sepsis process, four from hypertensive disorder, and one, from obstetric haemorrhage.

In a lineal regression model with creatinine, Kirby, and platelets as predictive variables for maternal death, R2 was 0.039, corrected R2 was 0.026, and Analysis of variance (ANOVA) was 0.028 . The following values were calculated with a 4-stepwise Cox Forward Regression model: cardiac dysfunction $(\mathrm{p}=0.099)$; haematological dysfunction $(\mathrm{p}=0.002)$; neurological dysfunction $(p=0.004)$, and Kirby $(p=0.035)$. Conversely, on ad- dressing the problem employing the Cox Backward Conditional model, results in step 15 were as follows: pre-eclampsia $(\mathrm{p}=0.042)$; transfusion $(\mathrm{p}=0.007)$; cardiac dysfunction $\quad(\mathrm{p}=0.067)$; respiratory dysfunction $(p=0.042)$; renal dysfunction $(p=0.014)$; haematological dysfunction $(\mathrm{p}=0.003)$; neurological dysfunction $(\mathrm{p}=0.006)$, and platelets $(\mathrm{p}=0.062)$ (Table 2$)$.

Table 2 Cox regression

\begin{tabular}{|l|l|l|}
\hline $\begin{array}{l}\text { Model and } \\
\text { steps }\end{array}$ & Failure & p-value \\
\hline Forward & & \\
\hline $\mathbf{1}$ & Cardiac & 0.001 \\
\hline $\mathbf{2}$ & Cardiac & 0.006 \\
& Hematological & 0.032 \\
\hline $\mathbf{3}$ & Cardiac & 0.030 \\
& Hematological & 0.003 \\
& Neurological & 0.002 \\
\hline $\mathbf{4}$ & Cardiac & 0.099 \\
& Hematological & 0.002 \\
& Neurological & 0.004 \\
& Kirby & 0.035 \\
\hline Backward & & \\
\hline $\mathbf{1 5}$ & Preeclampsia & 0.042 \\
& Transfusion & 0.007 \\
& Cardiac dysfunction & 0.067 \\
& Respiratory dysfunction & 0.042 \\
& Renal dysfunction & 0.014 \\
& Hematological dysfunction & 0.003 \\
& Neurological dysfunction & 0.006 \\
& Platelets & 0.062 \\
\hline
\end{tabular}

Systolic, diastolic, and mean arterial blood pressures were $128.7 \pm 25.7,81.6 \pm 18.9$, and $97.3 \pm 20.5 \mathrm{mmHg}$, respectively. Variables included in the SOFA scale presented the following mean \pm SD values: $\mathrm{PaO}_{2}: 100 \pm 40$; Kirby testing: $299.8 \pm 117.9$; creatinine: $1.2 \pm 2.1$; total bilirubin: $1.1 \pm 1.5$, and platelets: $170,004 \pm 120,113$. Mean creatinine clearance was $95.6 \pm 97.5 \mathrm{ml} / \mathrm{min}$. Interestingly, while the mean - 1SD values for Kirby (181.5) and platelet count $(49,890)$ were nearest to the column of 3 points of the SOFA scale, the mean + 1SD values for creatinine and bilirubin were nearest to the column of 2 points. Furthermore, the mean + 2SD for creatinine fit into the column of 3 points but that of bilirubin did so in the column of 2 points. Lastly, the mean - 2SD of Kirby decreased to 63.91 .

Complementary data analysis with Receiver operating curves (ROC) for the event "maternal death", offered statistical differences in the following variables: creatinine (0.048), $\mathrm{FiO}_{2}(0.025)$ and Kirby (0.06). Based on the latter result, a modified SOFA scale was constructed adjusting the value of 180 instead of 200 in the punctuation column of 3 points for the $\mathrm{PaO}_{2} / \mathrm{FiO}_{2}$ ratio and adding a file of disease evolution time with sepsis prior to reaching specialized medical attention.

The threshold of 12 hours was based on our experience of being a referral center registering fatal evolutions 
when it took more than that period of time for a preg- $\quad$ specialized medical attention (Table 3). nant woman with the diagnosis of sepsis before reaching

Table 3 Modified SOFA scale

\begin{tabular}{|c|c|c|c|c|c|}
\hline & 0 & 1 & 2 & 3 & 4 \\
\hline $\begin{array}{l}\text { Respiration }^{\mathrm{a}} \\
\mathrm{PaO}_{2} / \mathrm{FiO}_{2}(\mathrm{~mm} \mathrm{Hg}) \\
\mathrm{SaO}_{2} / \mathrm{FiO}_{2}\end{array}$ & $>400$ & $<400221-301$ & $\begin{array}{l}<300 \\
142-220\end{array}$ & $\begin{array}{l}<180 \\
67-141\end{array}$ & $\begin{array}{l}<100 \\
<67\end{array}$ \\
\hline $\begin{array}{l}\text { Coagulation } \\
\text { Platelets }\left(\mathbf{1 0}^{\mathbf{3}} / \mathbf{m m}^{\mathbf{3}}\right)\end{array}$ & $>150$ & $<150$ & $<100$ & $<50$ & $<20$ \\
\hline $\begin{array}{l}\text { Liver } \\
\text { Bilirubin (mg/dl) }\end{array}$ & $<1.2$ & $1.2-1.9$ & $2.0-5.9$ & $6.0-11.9$ & $>12.0$ \\
\hline $\begin{array}{l}\text { Cardiovascular }^{\mathrm{b}} \\
\text { Hypotension }\end{array}$ & No hypotension & $\mathrm{MAP}<70$ & $\begin{array}{l}\text { Dopamine } \leq 5 \text { or } \\
\text { dobutamine (any) }\end{array}$ & $\begin{array}{l}\text { Dopamine }>5 \text { or } \\
\mathrm{NE} \leq 0.1\end{array}$ & $\begin{array}{l}\text { Dopamine }>15 \text { or } \\
\mathrm{NE}>0.1\end{array}$ \\
\hline $\begin{array}{l}\text { CNS } \\
\text { Glasgow Coma Score }\end{array}$ & 15 & $13-14$ & $10-12$ & $6-9$ & $<6$ \\
\hline $\begin{array}{l}\text { Renal } \\
\text { Creatinine (mg/dl) } \\
\text { or urine output (mL/d) }\end{array}$ & $<1.2$ & $1.2-1.9$ & $2.0-3.4$ & $\begin{array}{l}3.5-4.9 \\
\text { or }<500\end{array}$ & $\begin{array}{l}>5.0 \\
\text { or }<200\end{array}$ \\
\hline Sepsis & absent & absent & absent & $\begin{array}{l}\text { present }< \\
12 \text { hours }\end{array}$ & $\begin{array}{l}\text { present }> \\
12 \text { hours }\end{array}$ \\
\hline
\end{tabular}

CNS: central nervous system; MAP: mean arterial pressure; $\mathrm{NE}$ : norepinephrine, $\mathrm{SaO}_{2}$ : peripheral arterial oxygen saturation. a: $\mathrm{PaO}_{2} / \mathrm{FiO}_{2}$ ratio preferentially, if not available, the $\mathrm{SaO}_{2} / \mathrm{FiO}_{2}$ ratio is optional. b: vasoactive mediations administered for at least $1 \mathrm{hr}$ (dopamine and norepinephrine, $\mu \mathrm{g} / \mathrm{kg} / \mathrm{min}$ ).

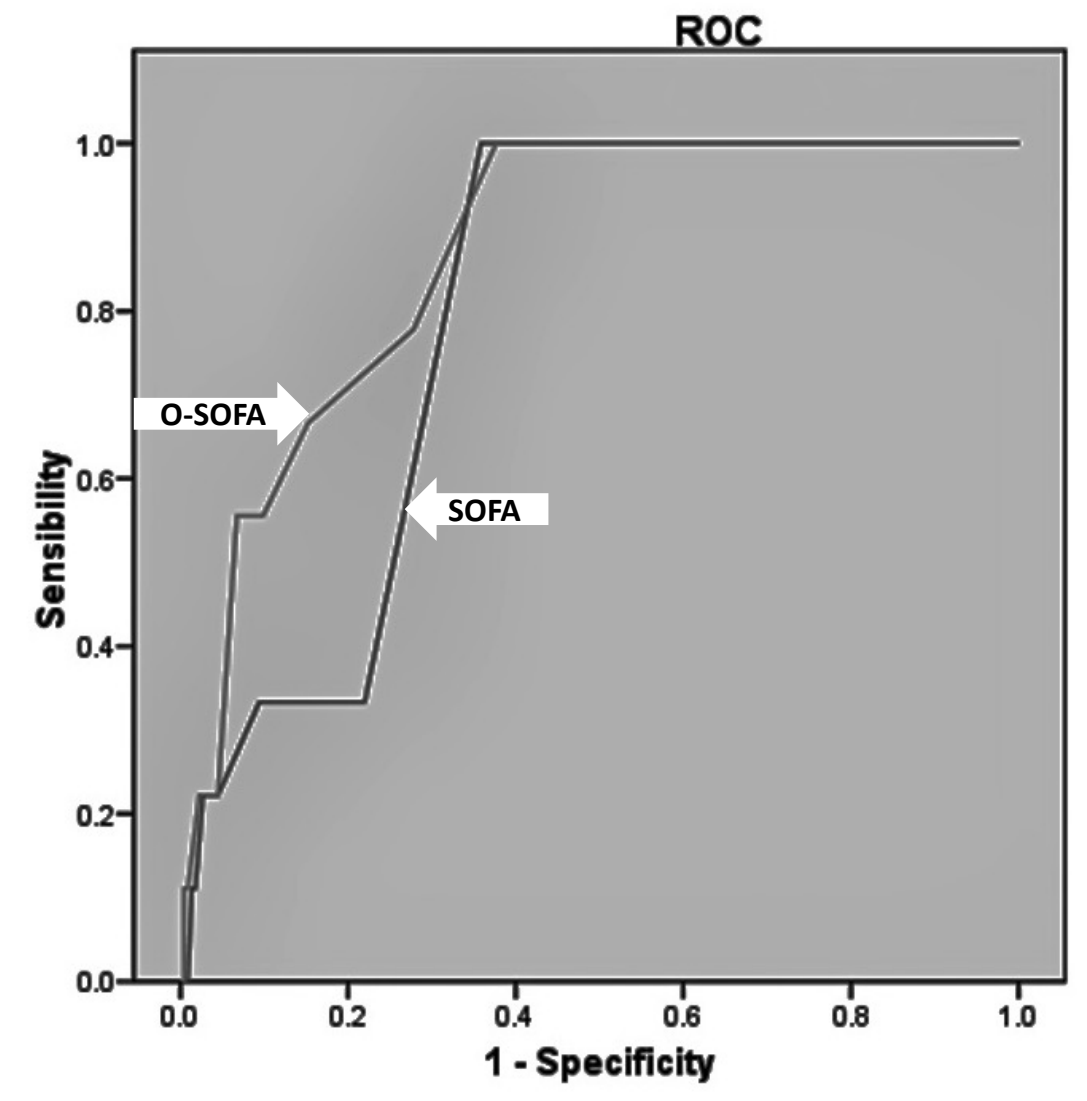

Figure 1 ROC curves for SOFA and O-SOFA.

SOFA area $=0.796$, sig. 0.003 (95\% CI 0.704-0.888); O-SOFA area $=0.868$, sig. $<0.001$ (95\% CI 0.763-0.954).

To illustrate this approach, ROC curves of SOFA and O-SOFA are depicted in Figure 1, with a higher area under the curve $(A U C)$ for O-SOFA $(0.868 ; \mathrm{p}<0.001)$ 
than SOFA (0.796; $p=0.003)$. Even more so, by changing the value of 100 for the $\mathrm{PaO}_{2} / \mathrm{FiO}_{2}$ ratio in the column of 4 points by 63 (mean - 2SD), the AUC (0.876) was higher than that for SOFA but lower than O-SOFA. Finally, the Cox Backward Conditional model in a step 2 yielded $\mathrm{p}<0.001$ for O-SOFA.

\section{DISCUSSION}

Maternal death is a public health problem and an indicator of the developmental level of a country. In fact, the study of near-miss cases has been employed to evaluate the quality of obstetrical health care systems. ${ }^{17}$

In polyvalent Intensive care units (ICU), sepsis plays a primary role as cause of death. ${ }^{18,19}$ Internationally, recent reports of the major factor predisposing to maternal morbidity include severe haemorrhage $28-56 \%$, hypertension $13-40 \%$, and sepsis, $3 \%{ }^{20-23}$ In our study, among direct causes of death, severe pre-eclampsia and sepsis were equally registered (four cases each), followed by obstetric haemorrhage. This report that contrasts with worldwide statistics could be due to that we have the Blood Bank Service at our Institution, which aids in fighting against imminent death in case of haemorrhage.

There are scores similar to those of SOFA, such as the Multiple Organ Dysfunction Score (MODS) ${ }^{24}$ and the "Brussels Score", the latter focused on sepsis. ${ }^{25}$ A major difference among the three scores lies in the definition of cardiovascular dysfunction/failure. MODS is based on the complex calculation of pressure adjusted to heart rate, while the "Brussels Score" is based on hypotension and acidemia. In the SOFA score, cardiovascular dysfunction/failure is based on the requirements for adrenergic support.

As previously noted, a worldwide accepted obstetrical morbid-mortality scale continues to be lacking. Despite that the SOFA score exhibits good prognostic value in obstetrical patients, it should not be considered definitive. The most important physiological parameter that seems to be adjusted is $\mathrm{PaO}_{2} / \mathrm{FiO}_{2}$; besides, in developing countries where a delay in specialized medical attention is common, it appears necessary to make an adjustment in cases of sepsis. In an initial attempt; we propose such adjustments with the O-SOFA. Resuming it possesses two changes; first, the lower value (180) of $\mathrm{PaO}_{2} / \mathrm{FiO}_{2}$ in the column of 3 points, based on the decreased pulmonary capacity in pregnancy and being the mean - 1SD value for Kirby, second, adding the file of time with sepsis. Following this corrections the sensitivity and specificity for the prediction of maternal death was better than with the known SOFA score.
Efforts are being made to assess and improve the quality and interpretation of routinely collected data, which will eventually lead us to a better obstetrical scale. It is worth noting that our study was developed through an open access data sheet in order to facilitate the data entry of each patient. We think, by employing a similar program, a multinational obstetric study group could increase casuistry.

Finally, this study entertains some limitations that should be mentioned. First, as a tertiary-level hospital, we have a Blood Bank Service that has exerted a great impact on the reduction of maternal mortality attributed to haemorrhage; without this Blood Bank Service, the targets in recovering from hypovolemic shock should be compromised. Second, the O-SOFA score does not demonstrate a high difference in total scoring of the population, meaning that, perhaps, the disease evolution time for sepsis should be considered a constant coefficient for multiplication of the SOFA value. Despite these limitations, the study possesses a number of strengths. First, it comprises the result of a specialized unit in providing care for obstetrical morbidity. Second, we propose the implementation of an open access data sheet in order to develop an international collaboration in the study of maternal mortality.

\section{CONCLUSIONS}

Establishing the prognosis and therapeutic conduct in the ICU is mandatory; however, in the obstetric patient, the influence of physiological changes renders it difficult to establish reference values for the scales already in use.

When compared with the SOFA scale, the O-SOFA that we propose here engenders encouraging results. However, we think it is possible to make adjustments in this direction, inviting more institutions to add their data to a common data sheet in order to develop, in a short amount of time, a better prognosis scale. It is our hope that sharing open access to specialized data could be the route to designing a worldwide-acceptable prognostic scale in obstetrical patients. It would also lead to interventions, aimed at increasing the awareness of danger signs among health providers at lower-level facilities, in order to minimize delays in referrals, to prevent both maternal morbidity and mortality.

This study further establishes a role for exploring the option for administering antibiotic prophylaxis in the third trimester of pregnancy to high-risk women as health-care guide policy for reducing extremely high mortality due to sepsis, even at tertiary-level hospitals. 
This action should be evaluated at the primary level of medical assistance, whenever there is suspicion of infection or when one expects a delay in specialized obstetric attention, in that a $>12-h$ evolution of sepsis dramatically reduces the survival outcome in critical patients.

\section{ACKNOWLEDGEMENT}

Authors thank the facilities of the "Mónica Pretelini Sáenz" Maternal-Perinatal Hospital (HMPMPS), to develop this study and Maggie Brunner M.A., for her excellent help with the English style correction.

\section{REFERENCES}

1. Paruk F, Moodley J. Severe obstetric morbidity. Curr Opin Obstet Gynecol. 2001;13:563-568.

2. Darmstadt GL, Marchant T, Claeson M, Brown W, Morris S, Donnay F, Taylor M, Ferguson R, Voller S, Teela KC, Makowiecka K, Hill Z, ManghamJefferies L, Avan B, Spicer N, Engmann C, TwumDanso N, Somers K, Kraushaar D, Schellenberg J. A strategy for reducing maternal and newborn deaths by 2015 and beyond. BMC Pregnancy Childbirth. 2013;13:216.

3. Peralta Sánchez A. [Maternal deaths in Mexico: a question of attitude]. Ginecol Obstet Mex. 2014;82:394-6.

4. Thorsen VC, Meguid T, Sundby J, Malata A. Components of maternal healthcare delivery system contributing to maternal deaths in Malawi: a descriptive cross-sectional study. Afr $J$ Reprod Health. 2014;18:16-26.

5. Desai M, Phillips-Howard PA, Odhiambo FO, Katana A, Ouma P, Hamel MJ, Omoto J, Macharia S, van Eijk A, Ogwang S, Slutsker L, Laserson KF. An analysis of pregnancy-related mortality in the KEMRI/CDC health and demographic surveillance system in western Kenya. PloS One. 2013;8:e68733.

6. Shah IH, Say L. Maternal mortality and maternity care from 1990 to 2005: uneven but important gains. Reprod Health Matters. 2007;15:17-27.

7. Filippi V, Ronsmans C, Campbell OM, Graham WJ, Mills A, Borghi J, Koblinsky M, Osrin D. Maternal health in poor countries: the broader context and a call for action. Lancet. 2006;368:1535-1541.

8. Geier F, Popp S, Greve Y, Achterberg A, Glöckner E, Ziegler R, Heppner HJ, Mang H, Christ M. Severity illness scoring systems for early identification and prediction of in-hospital mortality in patients with suspected sepsis presenting to the emergency department. Wien Klin Wochenschr. 2013;125:508-515.

9. Turner PL, Ilano AG, Zhu Y, Johnson SB, Hanna N. ACS-NSQIP criteria are associated with APACHE severity and outcomes in critically ill surgical patients. J Am Coll Surg. 2011;212:287294.

10. Say L, Souza JP, Pattinson RC; WHO working group on Maternal Mortality and Morbidity classifications. Maternal near miss--towards a standard tool for monitoring quality of maternal health care. Best Pract Res Clin Obstet Gynaecol. 2009;23:287296.

11. Vincent JL, Moreno R, Takala J, Willatts S, De Mendonça A, Bruining H, Reinhart CK, Suter PM, Thijs LG. Intensive Care Med. 1996;22:707-710.

12. Pérez A, Acevedo O, Tamayo F del C, Oviedo R. Characterization of obstetric patients with multiple organ failure in the intensive care unit of a Havana teaching hospital, 1998 to 2006. MEDICC Rev. 2010;12:27-32.

13. Albright CM, Ali TN, Lopes V, Rouse DJ, Anderson BL. The Sepsis in Obstetrics Score: a model to identify risk of morbidity from sepsis in pregnancy. Am J Obstet Gynecol. 2014;211:39 e1-8.

14. Gabrysch S, Cousens S, Cox J, Campbell OM. The influence of distance and level of care on delivery place in rural Zambia: a study of linked national data in a geographic information system. PLoS Med. 2011;8:e1000394.

15. Protocolo de Tésis - Índice de Mortalidad Materna. Available at: http://jorgemacia.net/TesisLulu

16. Bone RC. The sepsis syndrome. Definition and general approach to management. Clin Chest Med. 1996; 17:175-781.

17. Pattinson RC, Hall M. Near misses: a useful adjunct to maternal death enquiries. $\mathrm{Br}$ Med Bull. 2003;67:231-243.

18. Desai S, Lakhani JD. Utility of SOFA and APACHE II score in sepsis in rural set up MICU. $J$ Assoc Physicians India. 2013;61:608-611.

19. Sakr Y, Elia C, Mascia L, Barberis B, Cardellino S, Livigni S, Fiore G, Filippini C, Ranieri VM. Epidemiology and outcome of sepsis syndromes in Italian ICUs: a multicentre, observational cohort study in the region of Piedmont. Minerva Anestesiol. 2013;79:993-1002.

20. Geller SE, Rosenberg D, Cox SM, Brown ML, Simonson L, Driscoll CA, Kilpatrick SJ. The continuum of maternal morbidity and mortality: factors associated with severity. Am J Obstet Gynecol. 2004;191:939-944.

21. Brace V, Penney G, Hall M. Quantifying severe maternal morbidity: a Scottish population study. BJOG. 2004;111:481-484.

22. Sheldon WR, Blum J, Vogel JP, Souza JP, Gülmezoglu AM, Winikoff B; WHO Multicountry Survey on Maternal and Newborn Health Research Network. Postpartum haemorrhage management, risks, and maternal outcomes: findings from the World 
Health Organization Multicountry Survey on Maternal and Newborn Health. BJOG. 2014;121 Suppl 1:5-13.

23. Rana A, Baral G, Dangal G. Maternal near-miss: a multicenter surveillance in Kathmandu Valley. JNMA J Nepal Med Assoc. 2013;52:299-304.
24. Marshall JC, Cook DJ, Christou NV, Bernard GR, Sprung CL, Sibbald WJ. Multiple organ dysfunction score: a reliable descriptor of a complex clinical outcome. Crit Care Med. 1995;23:1638-1652.

25. Bernard G. The Brussels score. Sepsis. 1997;4:4344. $\bullet$ 